\title{
Interleukin-1 associations in inflammatory bowel disease and the enteropathic seronegative spondylarthritis
}

\author{
Periklis Vounotrypidis - Georgios Kouklakis - Konstantinos Anagnostopoulos • \\ Petros Zezos • Alexandros Polychronidis • Efstratios Maltezos • Eleni Efremidou • \\ Michael Pitiakoudis • Nikolaos Lyratzopoulos
}

Received: 7 October 2012/ Accepted: 4 February 2013/Published online: 22 February 2013

(C) Springer-Verlag Italia 2013

\begin{abstract}
Purpose This study aims to investigate any associations of the proinflammatory cytokine IL-1 in treated patients with inflammatory bowel disease (IBD) and the enteropathic seronegative spondylarthritis (eSpA).

Methods Thirty-four patients with Crohn's disease (CD), 26 with ulcerative colitis (UC) and 14 patients with SpA participated in the study. Valid clinical indexes, CRP values and the endoscopic and histologic examination were used for the determination of disease activity. IL- $1 \alpha$, IL-1 $\beta$, IL-1 receptor antagonist (IL-1Ra) were measured by ELISA. Nonparametric tests were used for continuous and categorical data.

Results Enteropathic SpA diagnosed in $29.4 \% \mathrm{CD}$ and $30.8 \%$ UC patients. Active disease had $58.8 \% \mathrm{CD}(\mathrm{aCD})$, $76.9 \% \mathrm{UC}$ and $50 \%$ SpA patients. Active and inactive CD (iCD) significantly differ on IL- $1 \alpha$ levels (11.2 vs. 3.9 pg/ $\mathrm{ml} ; p=0.034)$. Active and inactive $\mathrm{UC}$ significantly differ on IL-1 $\beta$ (3.7 vs. $2.3 \mathrm{pg} / \mathrm{ml} ; p=0.054)$ and IL-1Ra levels
\end{abstract}

P. Vounotrypidis $(\bowtie) \cdot$ G. Kouklakis · P. Zezos .

A. Polychronidis - E. Efremidou - M. Pitiakoudis ·

N. Lyratzopoulos

Department of Inflammatory Bowel Diseases, University

Hospital of Alexandroupolis, Democritus University of Thrace,

68100 Dragana, Alexandroupolis, Greece

e-mail: perivoun@email.com

\section{K. Anagnostopoulos}

Department of Medicine, Laboratory of Biochemistry, Democritus University of Thrace, 68100 Dragana,

Alexandroupolis, Greece

\section{E. Maltezos}

Department of Internal Medicine, University Hospital of Alexandroupolis, Democritus University of Thrace, 68100 Dragana, Alexandroupolis, Greece
( 15.9 vs. $12.7 \mathrm{pg} / \mathrm{ml} ; p=0.023$ ). Active and inactive SpA (iSpA) significantly differ on IL-1Ra (16.9 vs. $14.8 \mathrm{pg} / \mathrm{ml}$; $p=0.033)$ and marginally on IL- $1 \alpha$ levels (20 vs. $3.9 \mathrm{pg} /$ $\mathrm{ml} ; p=0.06)$. Patients with aCD/ieSpA exhibited significant differences on IL- $1 \alpha(p=0.022)$ compared to those with iCD/ieSpA.

Conclusions IL- $1 \alpha$ is associated with CD activity, while IL- $1 \beta$ and IL-1Ra are associated with UC activity in treated patients with IBD. Prominent cytokine in SpAs seems to be IL- $1 \alpha$.

Keywords Crohn's disease - Ulcerative colitis . Cytokines $\cdot$ Extra-intestinal manifestations

\section{Introduction}

Inflammatory bowel disease (IBD) and seronegative spondylarthritis ( $\mathrm{SpA}$ ) share common clinical characteristics and they frequently overlap. Some believe that they represent a different expression of the same disease based on common epidemiological, pathogenetic and clinical features such as the overlap of symptoms on a patient or the presence of different forms of seronegative spondylarthritis among family members [1].

Proinflammatory cytokines, particularly tumor necrosis factor alpha (TNF $\alpha$ ) and interleukin-1 (IL-1), are found to play a pivotal role during the acute phase response. Although treatment may modify the cytokine profile, this has not been studied extensively. In IBD, the disease process is divided into three phases-initiation, augmentation and perpetuation [2]. Rheumatologists, on the other hand, prefer to focus on clinical and radiological findings when they follow-up the evolution of SpAs. Despite treatment, there are frequent relapses in both conditions, and we 
hypothesize that proinflammatory cytokines have in any occasion the same cornerstone function, although such findings are not consistent [3].

This study is a combined gastroenterology and rheumatology approach aiming to investigate the role of IL-1 in treated patients with IBD and seronegative spondylarthritidis. It is an effort to analyze the prevalence of IL- 1 subtypes, interleukin-1 $\alpha$ (IL- $1 \alpha)$ and interleukin-1 $\beta$ (IL-1 $\beta$ ) as well as their antagonist receptor (IL-1Ra) in exacerbation and remission in patients with Crohn's disease (CD), ulcerative colitis (UC) and their associations with the enteropathic spondylarthritis (eSpA).

\section{Materials and methods}

\section{Study population}

Seventy-four adult patients with IBD and SpA (male/ female ratio: 48/26) fulfilled the inclusion criteria and enrolled in the study after informed consent was obtained. The study was approved by the Ethical Committee of the University Hospital of Alexandroupolis.

\section{Inclusion and exclusion criteria}

Patients had a definite diagnosis for Crohn's disease or ulcerative colitis according to conventional clinical, endoscopic and histologic criteria. Patients with seronegative spondylarthritis had a diagnosis of SpA according to ASAS criteria [4]. All patients were over 18 years of age, and they underwent an endoscopic evaluation at the time of assessment. This was a standard procedure for patients with IBD during the disease evaluation and follow-up. Individuals with SpA were examined endoscopically after their informed consent as it is known that up to seventy percent of SpA patients have abnormal intestinal pathology [5].

To eliminate any possible confounding factors on cytokine levels, patients were excluded if they had (1) an infectious disease prior to the evaluation month; (2) other immune-mediated diseases (bronchial asthma, allergies, etc.); (3) history of malignancy; (4) history of surgical intervention during the past 3 months and (5) presence of any other than arthritis extra-intestinal manifestation.

\section{Disease definitions}

Crohn's Disease Activity Index (CDAI) for CD, Simple Colitis Clinical Activity Index (SCCAI) for UC and the Bath Ankylosing Spondylitis Activity Index (BASDAI) for SpAs were used among with C-reactive protein and the endoscopic and histologic examination of intestinal biopsies for the estimation of disease activity.
Active disease for $\mathrm{CD}$ and $\mathrm{UC}$ is considered if (1) CDAI $>150$ and $\mathrm{SCCAI} \geq 2$, respectively, (2) presence of endoscopic activity (3) treatment with steroids $>5 \mathrm{mg}$ prednisone or equivalent steroid medication. If steroids were used under this level in stable or on tapered dose due to clinical and endoscopic remission, then IBD was considered inactive.

For patients with $\mathrm{SpA}$, the activity was defined by the presence of BASDAI $\geq 4$ or active peripheral arthritis on clinical examination by rheumatologist (PV).

Laboratory investigation

Serum samples were collected on the day of evaluation, before the endoscopic procedure and stored at $-40{ }^{\circ} \mathrm{C}$ until measurement. Interleukin- $1 \alpha$ (IL-1 $\alpha$ ), interleukin-1 $\beta$ (IL$1 \beta$ ), interleukin- 1 receptor antagonist (IL-1Ra) and $\mathrm{TNF} \alpha$ were measured by ELISA using the FIDIS Human Cytokine 10-plex kit (BMD Biomedical Diagnostics, Marne la Vallee, France). C-reactive protein (CRP) was measured by ELISA (normal values $<5 \mathrm{mg} / \mathrm{l}$ ), along with other routine laboratory parameters.

\section{Statistics}

The SPSS standard version 17.0 for Windows (SPSS Inc., USA) was used for the statistical analyses. The median values among with the 5th and 95th percentile position were estimated for variables in every group and subgroup of the study. Nonparametric tests were used for comparisons. The Mann-Whitney nonparametric test and the Fisher's exact test were used for comparisons between groups for continuous and categorical data, respectively. For comparisons of categorical data in more than two groups, the Kruskal-Wallis analysis of variance (ANOVA) was applied. The level of statistical significance was set to 0.05 .

\section{Results}

Baseline characteristics

CD was diagnosed in 34 patients, UC in 26 and SpA in 14 patients. All of them were in treatment with disease modifying drugs. The demographic and clinical data of patients are shown in Table 1.

According to endoscopy findings, the localization of intestinal disease in CD patients was characterized as small bowel involvement, large bowel involvement or mixed small and large bowel involvement. Ten patients $(29.4 \%)$ had small bowel, 8 patients $(23.5 \%)$ had colon and 16 patients $(47.1 \%)$ had combined small and large bowel 
Table 1 Demographic and clinical data of patients

\begin{tabular}{|c|c|c|c|}
\hline & $\begin{array}{l}\text { Crohn's } \\
\text { disease }\end{array}$ & $\begin{array}{l}\text { Ulcerative } \\
\text { colitis }\end{array}$ & $\begin{array}{l}\text { Arthritis } \\
\text { (SpA) }\end{array}$ \\
\hline Patients (N) & 34 & 26 & 14 \\
\hline $\operatorname{Sex}(M / F)$ & $22 / 12$ & $15 / 11$ & $11 / 3$ \\
\hline \multicolumn{4}{|l|}{ Age (years) } \\
\hline Median [range] & $32.5[18-61]$ & $42.5[23-70]$ & $34.5[23-65]$ \\
\hline \multicolumn{4}{|l|}{ BMI } \\
\hline Median [range] & $23.2[18-34]$ & $25.7[19-31]$ & $24.9[18-28]$ \\
\hline \multicolumn{4}{|l|}{ Disease duration (years) } \\
\hline Median [range] & $2[0.1-20]$ & $3[0.1-30]$ & $4[0.2-20]$ \\
\hline \multicolumn{4}{|l|}{ Disease localization } \\
\hline Small bowel & 10 & & 3 \\
\hline Large bowel & 8 & 26 & 2 \\
\hline Small and large bowel & 16 & & 2 \\
\hline \multicolumn{4}{|l|}{ IBD activity } \\
\hline Active & 20 & 20 & - \\
\hline Inactive & 14 & 6 & 7 \\
\hline Arthritis & 10 & 8 & \\
\hline Active & 5 & 4 & 10 \\
\hline Inactive & 5 & 4 & 4 \\
\hline \multicolumn{4}{|l|}{ Medications } \\
\hline ASA & 24 & 25 & 3 \\
\hline Corticosteroids & 26 & 10 & 5 \\
\hline AZA & 13 & 5 & 0 \\
\hline MTX & 0 & 0 & 4 \\
\hline Anti-TNF & 17 & 1 & 4 \\
\hline Combi medication (\%) & $28(82)$ & $13(50)$ & $2(14)$ \\
\hline
\end{tabular}

SpA Seronegative spondyloarthritis, ASA aminosalicylates, AZA azathioprine, MTX methotrexate, Anti-TNF anti-tumor necrosis factor alpha treatment

involvement. Patients with UC had solely involvement of the colon (no backwash ileitis). Seven out of 14 (50\%) patients with SpA had nonspecific histologic findings in intestinal biopsies from small and large bowel. Patients with SpA who were diagnosed with CD or UC automatically belonged to the IBD group, as enteropathic SpA.

Twenty patients $(58.8 \%)$ had active $\mathrm{CD}(\mathrm{aCD})$ and 20 (76.9 \%) had active UC (aUC) at the time of the evaluation. Fifty percent of IBD patients with enteropathic SpA $(n=18)$ had active arthritis (aeSpA), 5 in CD and 4 in UC groups. Nine SpA patients $(64.3 \%)$ had radiologically established ankylosing spondylitis, and 5 patients (35.7\%) had early spondylarthritis as defined by MRI plus peripheral arthritis.

All patients were on treatment while a large proportion $(58.1 \%)$ was in a combination of medications. Aminosalicylates were the main treatment in $\mathrm{CD}(76 \%)$ and in UC $(96.2 \%)$ and less favorable in arthritis patients $(21.4 \%)$. Medications included mesalazine (median $3 \mathrm{~g}$ daily, range 2-4) or sulphasalazine ( $2 \mathrm{~g}$ daily) and enema formulations in twelve active UC patients. Corticosteroids (prednisone or equivalent medication, median $20 \mathrm{mg} /$ day, range $2.5-40 \mathrm{mg} /$ day) were used in $76.5 \% \mathrm{CD}$ patients, $38.5 \% \mathrm{UC}$ and $35.7 \% \mathrm{SpA}$ patients; $28.6 \%$ of the later were also treated with methotrexate (median $10 \mathrm{mg} / \mathrm{week}$, range 7.5-12.5). Azathioprine received 18 (24.3\%) patients in a median dose $100 \mathrm{mg} /$ day, range $100-200 \mathrm{mg} /$ day. Anti-TNF treatment was applied more often to CD patients $(50 \%)$ and less commonly in arthritis (28.6\%) and UC $(3.8 \%)$ patients (Tables 1,2$)$. Those in anti-TNF treatment received infliximab $5 \mathrm{mg} / \mathrm{Kg}$ per body weight in bimonthly intravenous infusions or adalimumab $40 \mathrm{mg}$ subcutaneously every other week. Two patients in active $\mathrm{CD}$ received adalimumab in weekly injections. The median treatment duration was 14 months (range 2-90) for CD patients, 11.5 months (range 2-240) for UC patients and 13.5 months (range 3-48) for spondylarthritis patients.

Activity in IBD and arthritis

One of the main points of attention of this study is the overlap of IBD and arthritis in relation to clinical activity of both conditions. Patients were categorized according to disease activity in order to avoid misinterpretations in cytokine levels. A careful evaluation implementing clinical and endoscopic findings divided IBD patients in the groups that are shown in Table 2. The lower than the determined CDAI and SCCAI scores in some patients with active CD and UC were due to endoscopic activity.

The nonparametric Mann-Whitney test was used for comparisons between groups. Patients did not differ in age within groups except for patients with aUC and inactive UC (iUC, $p=0.055$ ). There was statistical difference between $\mathrm{aCD}$ and inactive $\mathrm{CD}$ (iCD) in relation to CDAI (153.5 vs. $75.5 ; p=0.024)$ and CRP (7.1 vs. $0.9 \mathrm{mg} / \mathrm{l}$; $p=0.014)$. There was also a significant difference between aUC and iUC in relation to SCCAI (4.5 vs. 1; $p=0.003)$ and CRP (6.1 vs. $0.5 \mathrm{mg} / \mathrm{l} ; p=0.011)$. In case of spondylarthritis, there was a statistical difference in the BASDAI between active SpA (aSpA) and inactive SpA (iSpA) (4.7 vs. $3.5 ; p=0.005)$ but not in CRP values (6.1 vs. $4.3 \mathrm{mg} / \mathrm{l} ; p=0.67$ ).

\section{Comparison of cytokines}

Initially, we evaluated the active and inactive forms of each disease. Due to the overlap of IBD and arthritis, we analyzed these conditions further having as primary criterion their activity. Distribution of these patients is shown on Table 3, and the comparisons that performed between with statistical results are shown in Table 4.

Between active $(n=20)$ and inactive CD $(n=14)$, there was statistical difference on IL- $1 \alpha$ levels (11.2 vs. 


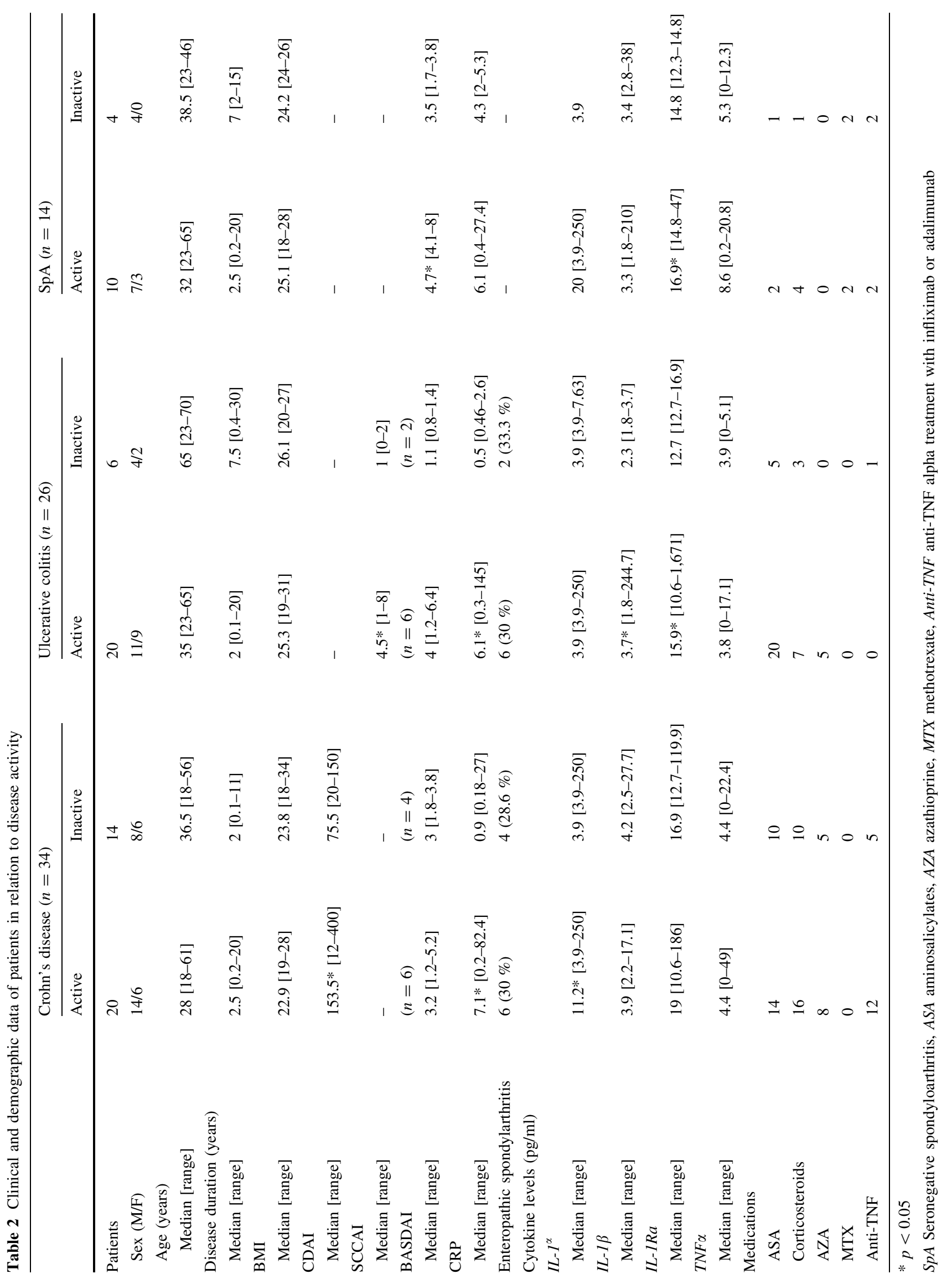


$3.9 \mathrm{pg} / \mathrm{ml} ; p=0.034)$, while there was no difference in other cytokines (IL-1 $\beta, p=0.28$; IL-1Ra, $p=0.75$; TNF $\alpha$, $p=0,94)$ (Table 2). In contrast, between active $(n=20)$ and inactive $(n=6) \mathrm{UC}$, there was no difference on IL-1 $\alpha$ levels $(p=0.28)$ but significant differences were observed on IL-1 $\beta$ (3.7 vs. $2.3 \mathrm{pg} / \mathrm{ml} ; p=0.054)$ and IL-1Ra (15.9 vs. $12.7 \mathrm{pg} / \mathrm{ml} ; \quad p=0.023)$. Interestingly, noteworthy variations were not found on TNFa levels $(p=0.58)$. Regarding arthritis, there was nearly statistical significance on IL- $1 \alpha$ levels between active $(n=10)$ and inactive $(n=4)$ forms of $\mathrm{SpA}(20$ vs. $3.9 \mathrm{pg} / \mathrm{ml} ; p=0.06)$ and significant difference on IL-1Ra (16.9 vs. $14.8 \mathrm{pg} / \mathrm{ml}$; $p=0.033)$. No differences were found on IL-1 $\beta(p=0.62)$ and TNF $\alpha(p=0.43)$ (Table 2). It is apparent that the activity of CD determines the cytokine pattern regardless of the presence of arthritis. IL- $1 \alpha$ has a cornerstone function at this point (Tables 2, 3, 4).

\section{Discussion}

Following initial reports 25 years ago [6], there is enough evidence today that IL-1 is together with TNF $\alpha$ the promoting cytokines of the inflammatory procedure in IBD and autoimmune arthritis [7, 8]. Seronegative spondylarthritis and the IBD share common features and they frequently overlap. Their correlation on cytokine level and specifically on IL-1 level has not yet been studied extensively.

Interleukin-1 exists in two forms, alpha and beta, and it is not clear if any of these contribute to a different extent to the phenotype of IBD including the presence of seronegative $\mathrm{SpA}$. Interleukin-1 receptor antagonist is required to minimize and balance the effects of active IL-1 forms.

We studied three groups of patients, the CD, UC and pure arthritis (SpA) group. We subdivided IBD patients according to the presence of arthritis and finally all groups according to disease activity in order to identify which cytokine from the IL-1 complex is involved in the disease exacerbation. All patients were on treatment, thus to be specific, the applied investigation refers to the phase of disease augmentation or perpetuation of IBD [2]. We adopted a rheumatology perception for disease remission where stable minimal doses of steroids considered as part of the disease modifying treatment and not just an antiinflammatory regimen, if full resolution of clinical, endoscopic and histologic findings was achieved.

We compared the groups without using controls of normal subjects because this has already been performed in other studies showing the impact of IL-1 and TNF in inflammatory procedure [6, 9, 10]. Furthermore, participants should undergo a full colonoscopy as a prerequisite for the enrolment in the study, thus an ethical dilemma for a group of normal subjects was deterrent.
In our cohort, the prevalence of arthritis in $\mathrm{CD}$ patients was $29.4 \%$ and in UC patients $30.8 \%$. Abnormal nonspecific intestinal pathology in patients with $\mathrm{SpA}$ was $50 \%$. CD was twice more common in males, and equal percentages on both sexes were found in UC. In arthritis group, there was a 3:1 ratio between males and females. The above demographic data of patients in our study are similar to those reported in medical literature.

Cytokine levels differ during disease activity, and this confirms their role as orchestrators of acute phase response. The innovation of this study is that it provides insights into role of the forms of IL- 1 in both IBD and seronegative spondylarthropathies. Distinctive disease-specific cytokine profiles were identified.

In Crohn's disease, IL- $1 \alpha$ mediates the exacerbations during treatment. Levels of IL- $1 \alpha$ were significantly higher in patients on active disease compared to remission (11.2 vs. $3.9 \mathrm{pg} / \mathrm{ml} ; p=0.034$ ), while no differences were observed on other cytokines.

The reverse phenomenon was observed in UC patients where IL-1 $\beta$ and IL-1Ra are the profound cytokines during exacerbations (3.7 vs. $2.3 \mathrm{pg} / \mathrm{ml} ; p=0.054$ and 15.9 vs. $12.7 \mathrm{pg} / \mathrm{ml} ; p=0.023$, respectively).

Patients with seronegative spondylarthropathy have a similar to the above both conditions pattern with IL- $1 \alpha$ and IL-1Ra playing a key role on disease exacerbations (20 vs. $3.9 \mathrm{pg} / \mathrm{ml} ; p=0.06$ and 16.9 vs. $14.8 \mathrm{pg} / \mathrm{ml} ; p=0.033$, respectively).

The two forms of IL-1 are on different transcriptional control, and this may explain the variances that were observed in CD and UC [11, 12]. Ludwiczek et al. [13] reported increased IL-1Ra plasma levels but not IL-1 $\alpha$ and IL-1 $\beta$ levels in unselected patients with $\mathrm{CD}$ and UC compared to healthy control subjects. In their study, colonic explant cultures exhibited increased levels of IL- $1 \alpha$ and IL-1Ra in non-lesional and lesional CD, lesional UC but not in non-lesional UC. They also found that IL-1 $\beta$ was elevated in lesional UC and CD but not in non-lesional CD. Thus, a subtle trend toward IL- $1 \alpha$ in CD and IL- $1 \beta$ in UC was noted. Leon et al. [14] reported that IL-1 $\beta$ levels are higher in affected areas compared to unaffected ones in UC patients but not in CD patients.

Correlating the clinical features of $\mathrm{CD}$ and UC with the pattern of IL- 1 forms, we could anticipate that IL- $1 \alpha$ may be a contributing factor to the fibrosing and granulosing procedure that is observed in CD, while IL-1 $\beta$ acts as a more potent immunoreactive cytokine. The latter is supported by studies which have shown that IL-1 $\beta$ mRNA in activated monocytes is over-expressed 25-50 times than IL- $1 \alpha$ [15]. Furthermore, the half-life of intracellular IL- $1 \beta$ is $15 \mathrm{~h}$ versus $2.5 \mathrm{~h}$ of IL-1 $\alpha$ [16]. The significantly higher levels of the IL-1Ra that we observed in patients with active UC are required to control and minimize the effects 


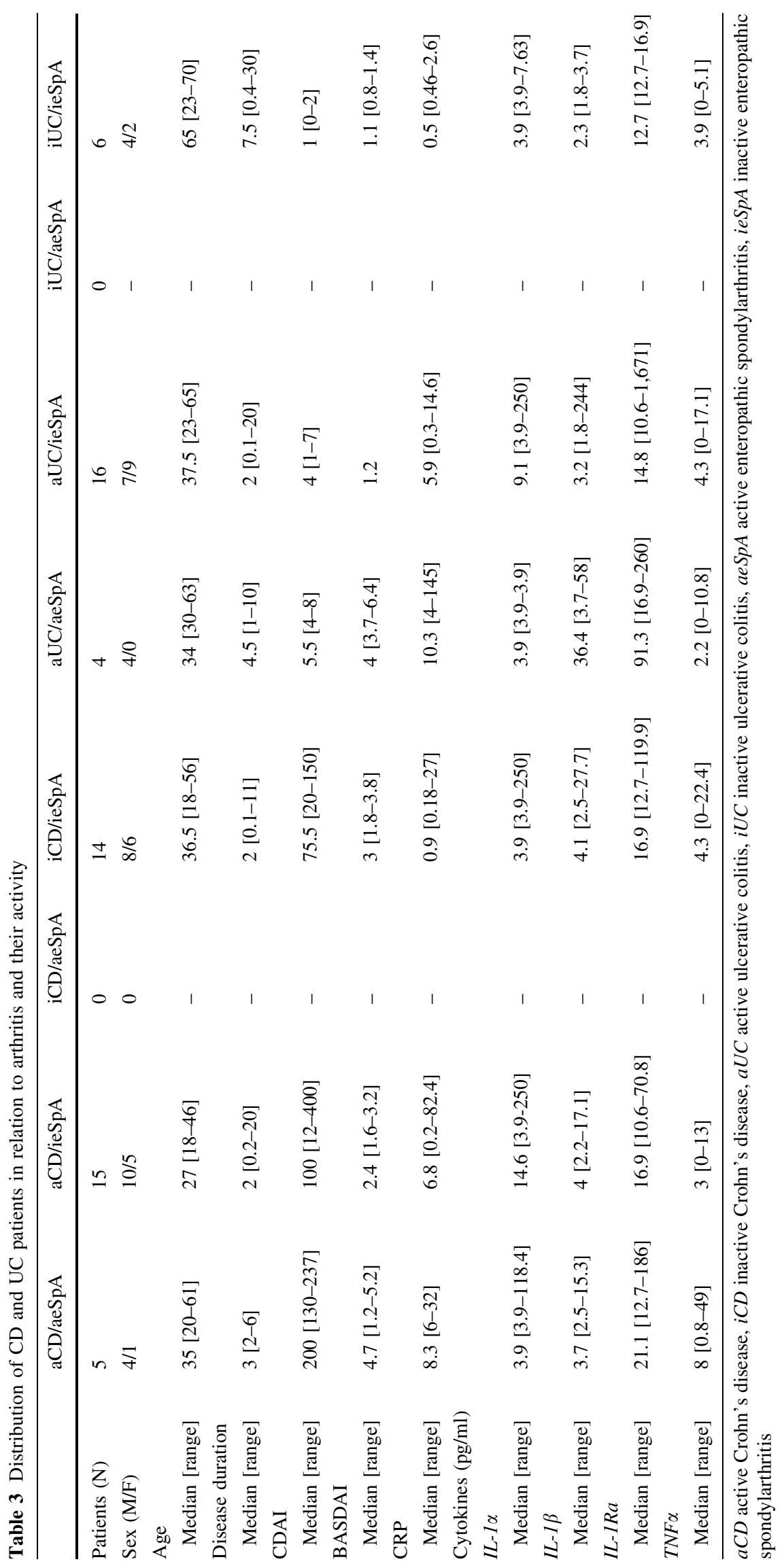


Table 4 Comparisons of cytokine median values (Tables 2, 3) between IBD and SpA groups. ( $p$ refers to Mann-Whitney $U$ test)

\begin{tabular}{|c|c|c|c|c|c|c|}
\hline \multicolumn{3}{|l|}{ Comparing groups } & \multirow{2}{*}{$\begin{array}{l}\mathrm{IL}-1 \alpha \\
p=0.034\end{array}$} & \multirow{2}{*}{$\frac{\mathrm{IL}-1 \beta}{\mathrm{NS}}$} & \multirow{2}{*}{$\frac{\text { IL-1Ra }}{\text { NS }}$} & \multirow{2}{*}{$\frac{\mathrm{TNF} \alpha}{\mathrm{NS}}$} \\
\hline${ }^{1} \mathrm{aCD}(n=20)$ & vs & $\operatorname{iCD}(n=10)$ & & & & \\
\hline${ }^{1} \mathrm{aUC}(n=20)$ & vs & $\mathrm{iUC}(n=6)$ & NS & $p=0.054$ & $P=0.023$ & NS \\
\hline${ }^{1} \mathrm{aSpA}(n=10)$ & vs & iSpA $(n=4)$ & $p=0.06$ & NS & $P=0.033$ & NS \\
\hline${ }^{2} \mathrm{aCD} / \mathrm{aeSpA}(n=5)$ & vs & aCD/ieSpA $(n=15)$ & NS & NS & NS & NS \\
\hline${ }^{2} \mathrm{aCD} / \mathrm{ieSpA}(n=15)$ & vs & $\mathrm{iCD} / \mathrm{ieSpA}(n=14)$ & $p=0.022$ & NS & NS & NS \\
\hline${ }^{1} \operatorname{aSpA}(n=10)$ & vs & ${ }^{3} \mathrm{iSpA}+\mathrm{ieSpA}(n=24)$ & $p=0.01$ & NS & NS & NS \\
\hline${ }^{4} \mathrm{aeSpA} \operatorname{sum}(n=9)$ & vs & ${ }^{1} \mathrm{aSpA}(n=10)$ & NS & NS & NS & NS \\
\hline
\end{tabular}

$I B D$ Inflammatory bowel disease, $a C D$ active Crohn's disease, $a U C$ active ulcerative colitis, $i C D$ inactive Crohn's disease, $i U C$ inactive ulcerative colitis, $S p A$ seronegative spondylarthritis, $e S p A$ spondylarthritis related to inflammatory bowel disease (enteropathic), aeSpA active enteropathic spondylarthritis, $i e S p A$ inactive enteropathic spondylarthritis, $N S$ not significant

${ }^{1}$ Groups and median values in Table 2

2 Groups and median values in Table 3

${ }^{3}$ Groups and median values in Tables 2 and 3 (sum of inactive SpA $(n=4)$, iCD/ieSpA $(n=14)$ and iUC/ieSpA $(n=6)$

${ }^{4}$ Groups and median values in Table 3 (sum of aCD/aSpA and aUC/aSpA)

of IL-1 $\beta$. The colon rather promotes a forceful immunostimulatory reaction, induced by IL- $1 \beta$, due to its microbial burden. Libby et al. [17] reported a maximal increase in IL-1 beta mRNA after exposure of human vascular smooth muscle cells to bacterial endotoxin. Animal models demonstrate the absence of colitis, gastritis and arthritis in a sterile environment, while both pathogenic and normal enteric microflora can induce and perpetuate chronic intestinal inflammation [18]. Quantitative changes as well as the functional activity of microbiota seem to be important in disease states [19]. The release of Th1-related proinflammatory cytokines IL- $1 \beta$ and TNF $\alpha$ has also been correlated with other chronic auto-immune and microbiallinked conditions [20,21].

We noted nearly significant difference on IL- $1 \alpha$ levels in active and inactive $\operatorname{SpAs}(p=0.06)$, and we assume that a greater number of patients would be clearly able to clarify this observation. There is recent evidence that IL- $1 \alpha$ gene polymorphisms are associated with susceptibility to ankylosing spondylitis [22]. Romero-Sanchez et al. [23] found that among twenty-two cytokines, IL- $1 \alpha$ was able to distinguish responders and non-responders of anti-TNF treatment. It would be very likely that ankylosis of the spine and in general the fibrosing properties of IL-1 exhibited via its alpha form. There is also enough knowledge to disassociate SpAs from IL-1 $\beta$. Gratacos et al. [24] were of the first groups that reported the lack of association of IL-1 $\beta$ to ankylosing spondylitis. Studies correlate IL-1 $\beta$ with rheumatoid arthritis rather than with SpA patients [25].

We did not find alterations on $\mathrm{TNF} \alpha$ levels during exacerbations in both IBD and SpAs, and these could be attributed to the effects of medication and the stage of perpetuation that were the majority of patients. Similar findings have been reported in medical literature $[3,26]$. The above suggest that IL-1 may act as an escape phenomenon of the inflammatory procedure during treatment and IL-1 forms mediate different pathways in IBD.

One of the limitations of this study is the relatively small cohort. A higher number of patients would be probably able to provide more striking differences, especially where a borderline insignificance was found. We considered that the primary criterion is the disease remission regardless of the type of medication. The number of patients did not allowed further study of the effects of treatment on cytokine profile. Another limitation mainly due to financial reasons is the omission of examining the IL-1RI and IL1RII receptors. This could further enhance our knowledge on IL-1 cytokines profile that is involved in IBD and SpAs.

The multidisciplinary approach of a "many faces" disease and the evaluation of patients in a custom clinical setting are among the strengths of the study. We enhanced the observations which declare that the two forms of IL-1 are probably differently acting cytokines.

In conclusion, the present study demonstrated that the alpha form of IL-1 is related to exacerbations in Crohn's disease, while the beta form of IL-1 is related to ulcerative colitis flares, during treatment of IBD patients. Seronegative spondylarthritis and enteropathic spondylarthritis correlate with the rise of IL-1 alpha and its receptor antagonist. IL- $1 \alpha$ may be responsible for the fibrosing skeletal and intestinal manifestations of seronegative spondylarthritis and Crohn's disease.

Acknowledgments This study supported by grant No. 1643/07 from Democritus University of Thrace, Alexandroupolis, Greece.

Conflict of interest Periklis Vounotrypidis, Georgios Kouklakis, Konstantinos Anagnostopoulos, Petros Zezos, Alexandros Polychronidis, 
Efstratios Maltezos, Eleni Efremidou, Michael Pitiakoudis, Nikolaos Lyratzopoulos declare that they have no conflict of interest.

Informed consent All procedures followed were in accordance with the ethical standards of the responsible committee on human experimentation (institutional and national) and with the Helsinki Declaration of 1975, as revised in 2008. Informed consent was obtained from all patients for being included in the study.

Animal studies No animal studies were carried out by the authors for this article.

\section{References}

1. Nash P, Mease PJ, Braun J, van der Heijde D (2005) Seronegative spondylarthropathies: to lump or to split? Ann Rheum Dis 64 (Suppl II):ii9-ii13

2. Mayer L (2010) Evolving paradigms in the pathogenesis of IBD. J Gastroenterol 45:9-16

3. Keller C, Webb A, Davis J (2003) Cytokines in the seronegative spondylarthropathies and their modification by TNF blockade: a brief report and literature review. Ann Rheum Dis 62:1128-1132

4. Sieper J, Rudwaleit M, Baraliakos X, Brandt J, Braun J, BurgosVargas R et al (2009) The Assessment of SpondyloArthritis international Society (ASAS) handbook: a guide to assess spondyloarthritis. Ann Rheum Dis 68:ii1-ii44

5. Mielants H, Veys EM, Cuvelier C, De Vos M, Goemaere S, De Clercq L, Schatteman L, Elewaut D (1995) The evolution of spondylarthropathies in relation to gut histology II. Histological aspects. J Rheumatol 22:2273-2278

6. Satsangi J, Wolstencroft RA, Cason J, Ainley CC, Dumonde DC, Thompson RP (1987) Interleukin 1 in Crohn's disease. Clin Exper Immunol 67:594-605

7. Dinarello CA, Gelfand JA, Wolff SM (1993) Anticytokine strategies in the treatment of the systemic inflammatory response syndrome. JAMA 269:1829-1835

8. Dinarello CA, Wolff SM (1993) The role of interleukin-1 in disease. N Engl J Med 328:106-113

9. Mahida YR, Wu K, Jewell DP (1989) Enhanced production of interleukin 1-beta by mononuclear cells isolated from mucosa with active ulcerative colitis of Crohn's disease. Gut 30:835-838

10. Brynskov J, Tvede N, Andersen CB, Vilien M (1992) Increased concentrations of interleukin $1 \beta$, interleukin-2, and soluble interleukin- 2 receptors in endoscopical mucosal biopsy specimens with active inflammatory bowel disease. Gut 33:55-58

11. Yamato K, el-Hajjaoui Z, Koeffler HP (1989) Regulation of levels of IL-1 mRNA in human fibroblasts. J Cell Physiol 139:610-616

12. Ohmori Y, Strassman G, Hamilton TA (1990) cAMP differentially regulates expression of mRNA encoding IL-1a and IL- $1 \mathrm{~b}$ in murine peritoneal macrophages. J Immunol 145:3333-3339
13. Ludwiczek O, Vannier E, Borggraefe I, Kaser A, Siegmund B, Dinarello CA, Tilg H (2004) Imbalance between interleukin-1 agonists and antagonists: relationship to severity of inflammatory bowel disease. Clin Exp Immunol 138:323-329

14. Leon AJ, Gomez E, Garrote JA, Bernardo D, Barrera A, Marcos JL et al (2009) High levels of proinflammatory cytokines, but not markers of tissue injury, in unaffected intestinal areas from patients with IBD. Mediators Inflamm 2009:580450. Epub 2009 Jul 30

15. Demczuk S, Baumberger C, Mach B, Dayer JM (1987) Expression of human IL1 alpha and beta messenger RNAs and IL1 activity in human peripheral blood mononuclear cells. J Mol Cell Immunol 5:255-265

16. Hazuda DJ, Lee JC, Young PR (1988) The kinetics of interleukin1 secretion from activated monocytes. Differences between interleukin 1 alpha and interleukin 1 beta. J Biol Chem 263: 8473-8479

17. Libby P, Ordovas JM, Birinyi LK, Auger KR, Dinarello CA (1986) Inducible interleukin-1 gene expression in human vascular smooth muscle cells. J Clin Invest 78:1432-1438

18. Sartor RB (1997) Enteric microflora in IBD: pathogens or commensals? Inflamm Bowel Dis 3:230-235

19. De Cruz P, Prideaux L, Wagner J et al (2012) Characterization of the gastrointestinal microbiota in health and inflammatory bowel disease. Inflamm Bowel Dis 18:372-390

20. Benagiano M, Azzurri A, Ciervo A, Amedei A, Tamburini C, Ferrari $M$ et al (2003) $\mathrm{T}$ helper type 1 lymphocytes drive inflammation in human atherosclerotic lesions. Proc Natl Acad Sci USA 100:6658-6663

21. Babolin C, Amedei A, Ozolins D, Zilevica A, D'Elios MM, de Bernard M (2011) TpF1 from Treponema pallidum activates inflammasome and promotes the development of regulatory T cells. J Immunol 187:1377-1384

22. Sims AM, Timms AE, Bruges-Armas J, Burgos-Vargas R, Chou CT, Doan T et al (2008) Prospective meta-analysis of interleukin 1 gene complex polymorphisms confirms associations with ankylosing spondylitis. Ann Rheum Dis 67:1305-1309

23. Romero-Sanchez C, Robinson WH, Tomooka BH, Londono J, Valle-Onate R, Huang F et al (2008) Identification of acute phase reactants and cytokines useful for monitoring infliximab therapy in ankylosing spondylitis. Clin Rheumatol 27:1429-1435

24. Gratacos J, Collado A, Filella X, Sanmarti R, Canete J, Liena J et al (1994) Serum cytokines (IL-6, TNF-alpha, IL-1 beta and IFN gamma) in ankylosing spondylitis: a dose correlation between serum IL-6 and disease activity and severity. Br J Rheumatol 33:927-931

25. Ganete JD, Martinez SE, Farres J, Sanmarti R, Blay M, Gomez A, Salvador G, Munoz-Gomez J (2000) Differential Th1/Th2 cytokine patterns in chronic arthritis: interferon $\gamma$ is highly expressed in synovium of rheumatoid arthritis compared with seronegative spondylarthropathies. Ann Rheum Dis 59:263-268

26. Sonel B, Tutkak H, Duzgun N (2002) Serum levels of IL-1beta, TNF-alpha, IL-8, and acute phase proteins in seronegative spondylarthropathies. Joint Bone Spine 69:463-467 